\title{
Porous MXenes Enable High Performance Potassium Ion Capacitors
}

Fangwang Ming, ${ }^{1}$ Hanfeng Liang, ${ }^{1}$ Wenli Zhang, ${ }^{1}$ Jun Ming, ${ }^{1}$ Yongjiu Lei, ${ }^{1}$ Abdul-Hamid Emwas, ${ }^{2}$ Husam N. Alshareef ${ }^{1, *}$

${ }^{1}$ Materials Science and Engineering, Physical Science and Engineering Division, King Abdullah University of Science and Technology (KAUST), Thuwal 23955-6900, Saudi Arabia

${ }^{2}$ Core Labs, King Abdullah University of Science and Technology (KAUST), Thuwal 239556900, Saudi Arabia 
ABSTRACT: High power $\mathrm{K}^{+}$ion capacitors have great potential in various large-scale applications because of the cost advantages and the low redox potential of $\mathrm{K} / \mathrm{K}^{+}$. However, the large ionic radius of potassium brings huge challenges for the development of suitable electrode materials. Here we demonstrate a general strategy for preparing porous MXene electrodes that can significantly enhance $\mathrm{K}^{+}$storage performance. Using $\mathrm{V}_{2} \mathrm{C}$ MXene as a model system, we show that the $\mathrm{K}^{+}$ion storage capacity can be greatly boosted by a simple sequential acid/alkali treatment. The resulting product, $\mathrm{K}-\mathrm{V}_{2} \mathrm{C}$, not only delivers a capacity of $195 \mathrm{mAh} \mathrm{g}^{-1}$ (in contrast to $98 \mathrm{mAh}$ $\mathrm{g}^{-1}$ of pristine $\mathrm{V}_{2} \mathrm{C}$ ) at $50 \mathrm{~mA} \mathrm{~g}^{-1}$, but also good rate performance. The charge storage mechanism was carefully studied and is shown to involve a solvent co-intercalation process. In addition, full cells were fabricated by coupling the $\mathrm{K}-\mathrm{V}_{2} \mathrm{C}$ anode and Prussian blue analogous $\left(\mathrm{K}_{x} \mathrm{MnFe}(\mathrm{CN})_{6}\right)$ cathode, which can work at a high average operating voltage of $\sim 3.3 \mathrm{~V}$ within a wide range $(0.01$ $\mathrm{V}$ to $4.6 \mathrm{~V}$ ). Moreover, the devices can achieve a high energy density of $145 \mathrm{Wh} \mathrm{kg}^{-1}$ at a power density of $112.6 \mathrm{~W} \mathrm{~kg}^{-1}$, suggesting that $\mathrm{K}-\mathrm{V}_{2} \mathrm{C}$, and other porous MXenes prepared by our approach, are promising electrodes in mobile ion capacitors.

Keywords: Porous MXene; $\mathrm{V}_{2} \mathrm{C}$ MXene; Potassium ion capacitor; Energy storage 


\section{Introduction}

With the growing concern about the depletion of fossil fuels and their environmental impact, demands for energy storage systems are rapidly increasing [1, 2]. Among existing energy storage technologies, lithium-ion batteries (LIBs) are considered the most promising owing to their high energy density and long cycle life $[3,4]$. Unfortunately, the grid-scale application of LIBs has been limited by uneven distribution, low abundance, and the increasing cost of lithium metal. Therefore, alternative energy storage systems are urgently needed, yet most remain challenging $[1,3]$. In this situation, a variety of new battery technologies have been proposed, such as Na-ion batteries (NIBs) [5-7], Mg-ion batteries [8, 9], and Zn-ion batteries [10-12]. Very recently, K-ion storage systems have received increasing attention because of the following advantages: a) compared with lithium, potassium is much more abundant (2.09 wt.\% for K vs. 0.0017 wt.\% for Li) in earth's crust [13]; b) the $\mathrm{K} / \mathrm{K}^{+}$couple possesses a redox potential of $-2.92 \mathrm{~V}$ (vs. standard hydrogen electrode), which is much lower than that of $\mathrm{Na} / \mathrm{Na}^{+}(-2.71 \mathrm{~V})$ and is close to that of $\mathrm{Li} / \mathrm{Li}^{+}(-3.04$ V), allowing potassium ion batteries to operate at a wider potential window and thus achieving higher energy density than NIBs [14-16]; c) potassium does not form alloys with aluminum. Hence, Al foil can be used as the current collector instead of copper, which can reduce overall battery cost [15]. However, the large ionic radius of $\mathrm{K}^{+}$leads to sluggish kinetics and dramatic volumetric expansion of the electrode materials, making it harder to achieve good electrochemical performance. In this regard, compounds with large open framework and/or interlayer spacing should be more promising electrode materials.

MXenes, a family of 2D (two-dimensional) layered compounds that are usually synthesized by selectively etching "A" off the layered "MAX" phases, where "M" is an early transition metal (e.g., Ti, V, Cr, Mo, and Nb), "A" is an A-group element (e.g., Al, Si, and Ga) and "X" is C and/or 
$\mathrm{N}$ [17]. MXenes have shown great potential in energy storage, such as mobile ion batteries and supercapacitors because of their high electrical conductivity, layered structure, large interlayer spacing, and rich surface/terminal functional groups [18-22]. Currently, one common issue of MXenes is that the single or few-layer 2D MXene nanosheets, exfoliated from the etched 3D (three-dimensional) counterpart, can easily restack and severely hamper electrolyte diffusion and permeation, resulting in unsatisfactory LIBs and NIB performance [23-25].

Synthesis of electrode materials with porous and/or hollow structures has been proven to be an effective means to boost the electrochemical performance, which could efficiently improve the electrolyte diffusion and permeation [24-27]. However, the synthesis of such MXene nanosheets remains a great challenge. Besides, the low coulombic efficiency $(\mathrm{CE})$ at the several initial cycles of the MXene electrodes is another big issue of their development for rechargeable batteries. More importantly, the storage mechanisms of MXene electrodes are still not fully understood but are critical for improving their electrochemical behavior.

Up to date, various MXenes have been developed, and the most studied one is $\mathrm{Ti}_{3} \mathrm{C}_{2}$, a compound that is relatively easy to synthesize and has found many exciting applications [28-30]. While other MXenes, such as $\mathrm{V}_{2} \mathrm{C}$ and $\mathrm{Nb}_{2} \mathrm{C}$, have considerably less been explored, they have shown great potential in energy storage applications, as demonstrated both theoretically [31-33] and experimentally [34-38]. In fact, $\mathrm{V}_{2} \mathrm{C}$ exhibits higher theoretical capacity than the well-studied $\mathrm{Ti}_{3} \mathrm{C}_{2}$ MXene for mobile ion batteries [31-33]. Also, $\mathrm{V}_{2} \mathrm{C}$ exhibits a high electronic conductivity of $3300 \mathrm{~S} \mathrm{~cm}^{-1}$ [39]. However, the utilization of $\mathrm{V}_{2} \mathrm{C}$ MXene for energy storage applications such as potassium ion battery/capacitor is still very limited, and the charge storage mechanism of these materials remains unexplored. 
In this work, we present a simple method involving dual acid/alkali treatment to prepare 3D porous accordion-like $\mathrm{V}_{2} \mathrm{C}$ MXene (henceforth referred to as $\mathrm{K}-\mathrm{V}_{2} \mathrm{C}$ to distinguish it from acidetched MXene or $\mathrm{V}_{2} \mathrm{C}$ ). We further investigate their electrochemical performance and charge storage mechanism for potassium ion capacitor applications. The dual acid/alkali treated product $\left(\mathrm{K}-\mathrm{V}_{2} \mathrm{C}\right)$ shows greatly enhanced performance with a high capacity of $152 \mathrm{mAh} \mathrm{g}^{-1}$ at a current density of $100 \mathrm{~mA} \mathrm{~g}^{-1}$ compared to the control sample, acid-treated $\mathrm{V}_{2} \mathrm{C}\left(72 \mathrm{mAh} \mathrm{g}^{-1}\right)$. The proposed strategy can be extended to other MXenes with porous nanosheet structure. Further, potassium ion capacitors were successfully fabricated by coupling the $\mathrm{K}-\mathrm{V}_{2} \mathrm{C}$ anode and $\mathrm{K}_{x} \mathrm{MnFe}(\mathrm{CN})_{6}$ cathode. The full cells could achieve the energy densities of 145, and $30.55 \mathrm{Wh}$ $\mathrm{kg}^{-1}$ at the power densities of 112.6 and $3026 \mathrm{~W} \mathrm{~kg}^{-1}$, respectively, suggesting the great potential of our material in practical energy storage devices.

\section{Results and Discussion}

The $\mathrm{K}-\mathrm{V}_{2} \mathrm{C}$ was prepared by a simple sequential acid/alkali treatment. As schematically shown in Figure 1A. Initially, $\mathrm{V}_{2} \mathrm{C}$ MXene was prepared by selectively etching $\mathrm{Al}$ from the $\mathrm{V}_{2} \mathrm{AlC}$ $\mathrm{MAX}$ in a mixture of $\mathrm{LiF}$ and $\mathrm{HCl}$. The as-obtained $\mathrm{V}_{2} \mathrm{C}$ powders were then treated by a $2 \mathrm{M} \mathrm{KOH}$ solution to get the $\mathrm{K}-\mathrm{V}_{2} \mathrm{C}$ MXene. The scanning electron microscopy (SEM) images of $\mathrm{V}_{2} \mathrm{AlC}$, $\mathrm{V}_{2} \mathrm{C}$, and $\mathrm{K}-\mathrm{V}_{2} \mathrm{C}$ (Figure 1B-D) clearly reveal a structural evolution from bulk solid MAX block (Figure 1B) to accordion-like MXene sheets (Figure 1C) upon acid etching. Interestingly, after alkali treatment, the MXene is further delaminated due to the intercalation of $\mathrm{K}^{+}$ions, resulting in much thinner MXene sheets, though the overall accordion-like structure of MXene is wellpreserved. Many pores and cracks are also observed in the $\mathrm{K}-\mathrm{V}_{2} \mathrm{C}$ MXene (marked by yellow dashed circles, Figure 1D-F, S1). This effect could be due to the highly corrosive nature of $\mathrm{KOH}$, which generates pores and cracks. The high-resolution transmission electron microscopy 
(HRTEM) images (Figure $\mathbf{1 G}$ and $\mathbf{H}$ ) confirm the good crystallinity of $\mathrm{K}-\mathrm{V}_{2} \mathrm{C}$, with measured spacing (101) plane spacing of $0.248 \mathrm{~nm}$. The selected area electron diffraction (SAED) pattern in Figure 1I indicates a hexagonal symmetry of the as-prepared $\mathrm{K}-\mathrm{V}_{2} \mathrm{C}$.

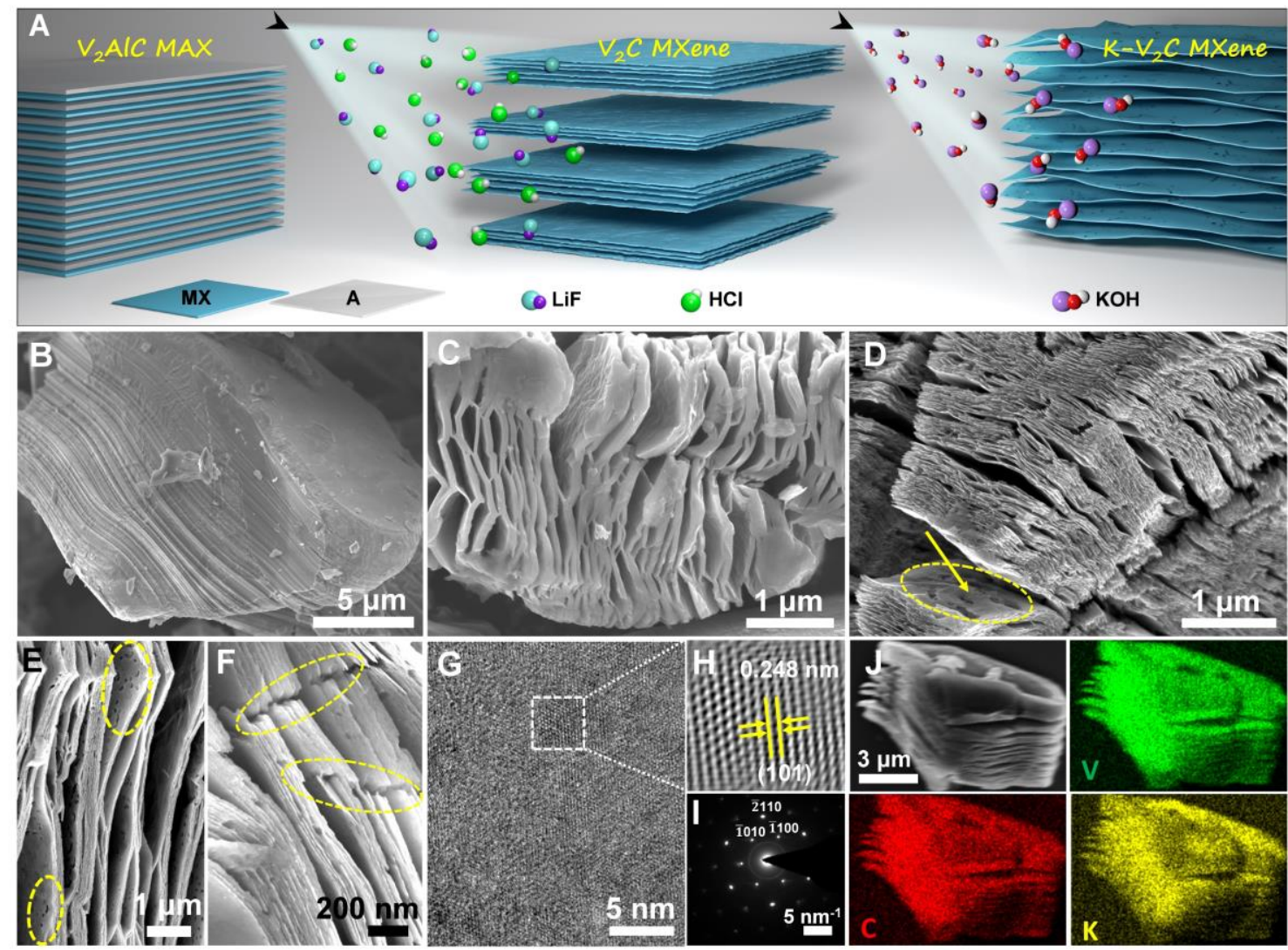

Figure 1. Synthesis process and structural characterization of $K-\mathrm{V}_{2} \mathrm{C}$ MXene. (A) Schematic illustration of the preparation process of $\mathrm{K}-\mathrm{V}_{2} \mathrm{C}$. SEM images of (B) $\mathrm{V}_{2} \mathrm{AlC}$, (C) $\mathrm{V}_{2} \mathrm{C}$, and (D-F) $\mathrm{K}-\mathrm{V}_{2} \mathrm{C}$. (G) HRTEM image, $(\mathrm{H})$ inverse Fourier-filtered image of the square marked in $\mathrm{F}$, and (I) the corresponding SAED pattern of the $\mathrm{K}-\mathrm{V}_{2} \mathrm{C}$. (J) SEM-EDS elemental maps of $\mathrm{K}-\mathrm{V}_{2} \mathrm{C}$. 

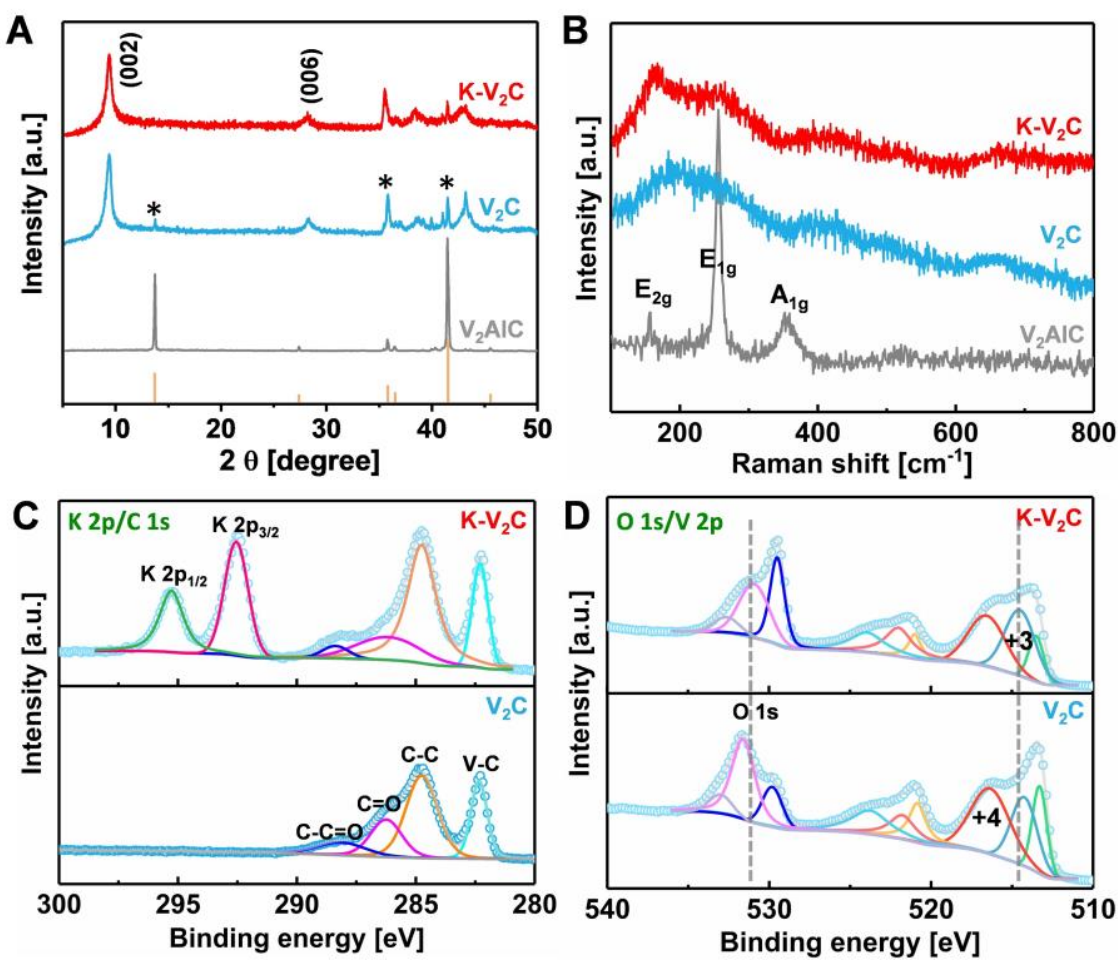

Figure 2. (A) XRD patterns and (B) Raman spectra of $\mathrm{V}_{2} \mathrm{AlC}, \mathrm{V}_{2} \mathrm{C}$, and $\mathrm{K}-\mathrm{V}_{2} \mathrm{C}$ MXenes. (C) XPS spectra of $\mathrm{K} 2 \mathrm{p}, \mathrm{C} 1 \mathrm{~s}$, and (D) $\mathrm{O} 1 \mathrm{~s}, \mathrm{~V} 2 \mathrm{p}$ regions of $\mathrm{V}_{2} \mathrm{C}$ and $\mathrm{K}-\mathrm{V}_{2} \mathrm{C}$.

The phase transition from $\mathrm{V}_{2} \mathrm{AlC}$ to $\mathrm{V}_{2} \mathrm{C}$ and $\mathrm{K}-\mathrm{V}_{2} \mathrm{C}$ was further studied by $\mathrm{XRD}$ and Raman analyses. Figure 2A shows the XRD patterns of the samples. It is obvious that the (002) peak of $\mathrm{V}_{2} \mathrm{C}$ shifts to lower two-theta angle compared to $\mathrm{V}_{2} \mathrm{AlC}$, suggesting an expanded interlayer spacing. After the alkali treatment, the XRD pattern of the resulting $\mathrm{K}-\mathrm{V}_{2} \mathrm{C}$ is similar to that of $\mathrm{V}_{2} \mathrm{C}$, while the diffraction peaks (marked by asterisks) of $\mathrm{V}_{2} \mathrm{AlC}$ MAX are weakened or vanished. It should be noted that after $\mathrm{KOH}$ treatment, the interlayer spacing of MXene slightly decreases from $\sim 9.5$ to $\sim 9.38 \AA$ (Figure S2). This might be due to the strong interactions of the intercalated $\mathrm{K}^{+}$and MXene layers that causes shrinkage of the interlayer distance. A similar phenomenon can also be found in $\mathrm{Nb}_{2} \mathrm{C}$ and $\mathrm{Ti}_{3} \mathrm{C}_{2}$ MXenes (Figure S5D, S6D). Raman spectra (Figure 2B) were further collected to study the phase information of the products. It should be noted that $\mathrm{V}_{2} \mathrm{C}$ MXene 
is quite sensitive to the Raman laser. Therefore, we collected the Raman spectra using $633 \mathrm{~nm}$ wavelength with the $10 \%$ power filter to avoid sample oxidation, but this results in the low signalto-noise ratio. The comparison between the Raman spectra of $\mathrm{V}_{2} \mathrm{AlC}$ MAX phase and the corresponding $\mathrm{V}_{2} \mathrm{C}$ MXene indicates an overall weakening of the peak intensity as well as a broadening of the peaks, probably due to the expanded interlayer spacing in MXene with respect to its MAX counterpart. Three peaks are identified in the $\mathrm{V}_{2} \mathrm{AlC}$ spectrum at $158\left(\mathrm{E}_{2 \mathrm{~g}}\right), 258\left(\mathrm{E}_{1 \mathrm{~g}}\right)$, and $360 \mathrm{~cm}^{-1}\left(\mathrm{~A}_{1 \mathrm{~g}}\right)[40,41]$. The first peak corresponds to in-plane vibrations of $\mathrm{V}$ and $\mathrm{Al}$ atoms, while the other two peaks correspond to in-plane and out-of-plane vibrations of $\mathrm{V}$ atoms [40, 41]. In contrast, after the acid treatment, the first peak $\left(E_{2 \mathrm{~g}}\right.$ at $\left.\sim 158 \mathrm{~cm}^{-1}\right)$ that corresponds to the inplane $\mathrm{V}$-Al vibration disappears because of the removal of $\mathrm{Al}$ atoms [40]. The other two peaks that correspond to the in-plane $\left(E_{1 \mathrm{~g}}\right)$ and out-of-plane $\left(A_{1 \mathrm{~g}}\right) \mathrm{V}$ atoms' vibration can still be found in $\mathrm{V}_{2} \mathrm{C}$ spectrum, but slightly shifted to $\sim 270$ and $420 \mathrm{~cm}^{-1}$, respectively. This shift might be due to the enlarged interlayer spacing and the rich surface functional groups (-F, -OH, -O) of MXene that change the chemical bonding environment. Our results are in good agreement with the previous experimental results and theoretical calculation [40]. After the alkali treatment, the Raman spectrum is similar to that of pristine $\mathrm{V}_{2} \mathrm{C}$ MXene except for a small peak that is observed at $\sim 165$ $\mathrm{cm}^{-1}$, which might be associated with the insertion of potassium ions and/or $\mathrm{V}-\mathrm{O}$ vibrations originating from surface oxidation $[42,43]$.

A comparison of the energy-dispersive $\mathrm{X}$-ray spectroscopy (EDS) spectra of the $\mathrm{V}_{2} \mathrm{C}$ and $\mathrm{K}$ $\mathrm{V}_{2} \mathrm{C}$ (Figure S3) suggests that the amount of $\mathrm{Al}$ is reduced while $\mathrm{K}$ is introduced during the alkali treatment. This result confirms further etching of residual $\mathrm{Al}$ and insertion of $\mathrm{K}^{+}$ions in the MXenes. The $\mathrm{K}: \mathrm{V}$ ratio (in $\mathrm{K}-\mathrm{V}_{2} \mathrm{C}$ ) was determined to be $0.11: 1$ by inductively coupled plasma 
optical emission spectrometer (ICP-OES). SEM-EDS elemental mapping (Figure 1J) demonstrates the homogenous distribution of $\mathrm{V}, \mathrm{C}$, and $\mathrm{K}$ in $\mathrm{K}-\mathrm{V}_{2} \mathrm{C}$. The chemical composition and oxidation states were then investigated by X-ray photoemission spectroscopy (XPS). As shown in Figure 2C, The $\mathrm{C}$ 1s core level region for $\mathrm{V}_{2} \mathrm{C}$ and $\mathrm{K}-\mathrm{V}_{2} \mathrm{C}$ can be divided into four peaks centered at around 282.3, 284.76, 286.2, and $288.4 \mathrm{eV}$, which can be assigned to $\mathrm{V}-\mathrm{C}, \mathrm{C}-\mathrm{C}$, $\mathrm{C}=\mathrm{O}$, and $\mathrm{O}-\mathrm{C}=\mathrm{O}$, respectively [37]. There is no signal in the $\mathrm{K} 2 \mathrm{p}$ region of the $\mathrm{V}_{2} \mathrm{C}$, whereas two sharp peaks emerged in the $\mathrm{K}-\mathrm{V}_{2} \mathrm{C}$ sample, which shows the successful introduction of $\mathrm{K}^{+}$ into the MXene host. In the V 2p (Figure 2D) region, the peak at the binding energy of $513.4 \mathrm{eV}$ corresponds to unreacted $\mathrm{V}_{2} \mathrm{AlC}$ MAX $[34,37]$. The peak area is reduced after the alkali treatment (the ratio of the fitted peaks $\left(\mathrm{V}^{4+} / \mathrm{V}^{3+} / \mathrm{V}\right.$ species) is $1: 0.7: 0.46$ for $\mathrm{V}_{2} \mathrm{C}$ and $1: 0.92: 0.36$ for $\mathrm{K}-$ $\mathrm{V}_{2} \mathrm{C}$, respectively) implying further etching of $\mathrm{Al}$, which is consistent with the XRD and EDS results discussed earlier. The increase of the $\mathrm{V}^{3+} / \mathrm{V}^{4+}$ peak area ratio (from 0.7 to 0.92 ) suggests a decrease in the $\mathrm{V}$ valence, revealing a partial reduction of vanadium upon $\mathrm{K}^{+}$insertion. Besides, the slight binding energy shifts of $\mathrm{O} 1 \mathrm{~s}$ (blue shift) and $\mathrm{V} 2 \mathrm{p}$ (redshift) may also be due to $\mathrm{K}^{+}$ insertion. Furthermore, three peaks are observed in the $\mathrm{O} 1 \mathrm{~s}$ region (at 529.8, 531.5, and $533 \mathrm{eV}$ ), which can be ascribed to mixed vanadium oxide, surface oxide functional groups, and intercalated water [34]. Note that there is a significant increase in the intensity of the first peak $(529.8 \mathrm{eV})$ upon $\mathrm{KOH}$ treatment, which could be due to the presence of thinner $\mathrm{K}-\mathrm{V}_{2} \mathrm{C}$ MXene sheets, which lead to a higher surface area and thus expose more oxidized surface and edges. Another possible reason is that the $\mathrm{KOH}$ treatment modifies the terminal functional groups. $\mathrm{N}_{2}$ adsorption-desorption isotherms measurement was carried out to determine the specific surface area and pore size distribution of the products. The Brunauer-Emmett-Teller (BET) surface area (Figure S4) are determined to be $28.4 \mathrm{~m}^{2} \mathrm{~g}^{-1}$ for $\mathrm{K}-\mathrm{V}_{2} \mathrm{C}$, which is almost twice that of pristine $\mathrm{V}_{2} \mathrm{C}\left(14.26 \mathrm{~m}^{2} \mathrm{~g}^{-1}\right)$. 
The pore size distribution plots also confirm the existence of pores in the $\mathrm{K}-\mathrm{V}_{2} \mathrm{C}$ sample. All these studies demonstrate that the potassium inserted porous $\mathrm{V}_{2} \mathrm{C}$ MXene (or $\mathrm{K}-\mathrm{V}_{2} \mathrm{C}$ ) can be obtained via a facile sequential acid/alkali treatment.

It is worth noting that not only $\mathrm{KOH}$ but other bases such as $\mathrm{LiOH}$ and $\mathrm{NaOH}$ (Figure S5) can be used for the alkali treatment to achieve similar porous structure and morphology of MXene, suggesting the flexibility of our method. To further explore the generality of this approach, we extended the synthesis to various MXenes (i.e., $\mathrm{Nb}_{2} \mathrm{C}$, $\mathrm{Ti}_{3} \mathrm{C}_{2}$ ). Delaminated $\mathrm{K}-\mathrm{Nb}_{2} \mathrm{C}$ MXene with thin sheets were readily obtained (Figure S6), consistent with what we have observed for $\mathrm{K}-\mathrm{V}_{2} \mathrm{C}$, confirming the versatility of our approach. Interestingly, for $\mathrm{K}-\mathrm{Ti}_{3} \mathrm{C}_{2}$, not only delaminated sheets but also many nanowires were obtained (Figure S7). These nanowires are likely amorphous titanium oxide resulting from the partial oxidation of $\mathrm{Ti}_{3} \mathrm{C}_{2}$, as demonstrated previously [44]. This result suggests that our sequential acid/alkali treatment is more efficient in etching MAX and in producing MXene thin sheets compared to commonly used acid-based etching methods. 

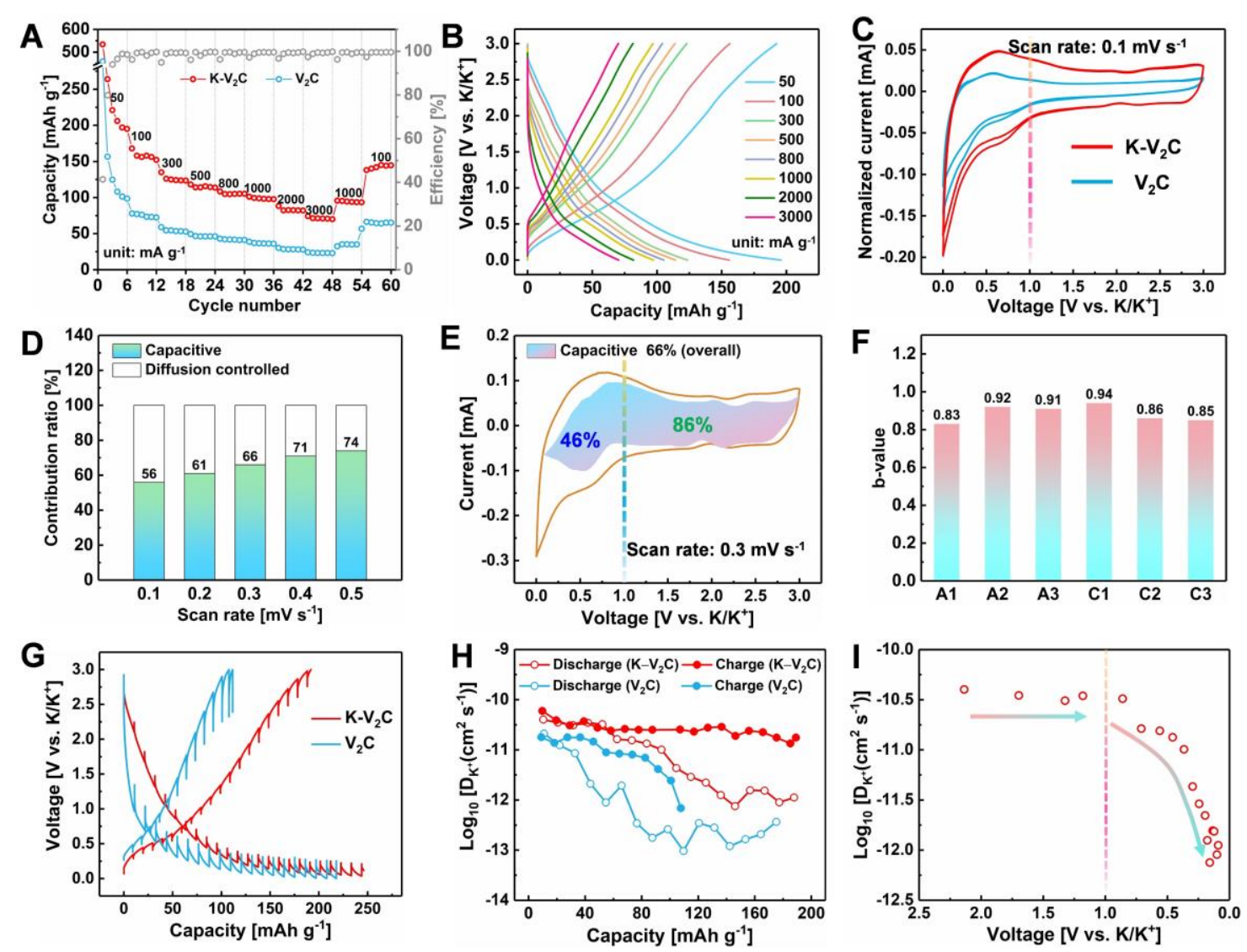

Figure 3. Electrochemical characterizations of $\mathrm{V}_{2} \mathrm{C}$ and $\mathrm{K}-\mathrm{V}_{2} \mathrm{C}$ MXenes. (A) Rate performance of $\mathrm{V}_{2} \mathrm{C}$ and $\mathrm{K}-\mathrm{V}_{2} \mathrm{C}$. (B) Galvanostatic charge/discharge curves at various current densities of the $\mathrm{K}-\mathrm{V}_{2} \mathrm{C}$. (C) $\mathrm{CV}$ curves of the second and third cycles of the $\mathrm{V}_{2} \mathrm{C}$ and $\mathrm{K}-\mathrm{V}_{2} \mathrm{C}$. (D, E) Capacity separation at different scan rates. (F) $b$-values of different redox peaks determined from the $\log (i)$ versus $\log (v)$ plots of $\mathrm{K}-\mathrm{V}_{2} \mathrm{C}$. (G) GITT curves and $(\mathrm{H})$ the calculated $\mathrm{K}^{+}$diffusion coefficients in the $\mathrm{V}_{2} \mathrm{C}$ and $\mathrm{K}-\mathrm{V}_{2} \mathrm{C}$ electrodes. (I) $\mathrm{K}^{+}$diffusion coefficients at various states during the discharging process of the $\mathrm{K}-\mathrm{V}_{2} \mathrm{C}$ electrode.

We then investigated the potassium ion storage performance of $\mathrm{V}_{2} \mathrm{C}$ and $\mathrm{K}-\mathrm{V}_{2} \mathrm{C}$. As shown in Figure 3A, B and S8, the $\mathrm{V}_{2} \mathrm{C}$ MXene delivers reversible discharge capacities of 98 ( $6^{\text {th }}$ cycle) and $72 \mathrm{mAh} \mathrm{g}^{-1}\left(12^{\text {th }}\right.$ cycle $)$ at 50 and $100 \mathrm{~mA} \mathrm{~g}^{-1}$, respectively. These numbers are already higher 
than those reported for $\mathrm{Ti}_{3} \mathrm{CN}$ at the same rates (65 and $52 \mathrm{mAh} \mathrm{g}^{-1}$, respectively) [45]. In comparison, the $\mathrm{K}-\mathrm{V}_{2} \mathrm{C}$ can achieve capacities of $195\left(6^{\text {th }}\right.$ cycle $)$ and $152 \mathrm{mAh} \mathrm{g}^{-1}\left(12^{\text {th }}\right.$ cycle $)$ at the current densities of 50 and $100 \mathrm{~mA} \mathrm{~g}^{-1}$, respectively. Moreover, the capacities of $97\left(36^{\text {th }}\right.$ cycle) and $70 \mathrm{mAh} \mathrm{g}^{-1}$ (48 ${ }^{\text {th }}$ cycle) can be obtained at high rates of 1000 and $3000 \mathrm{~mA} \mathrm{~g}^{-1}$, respectively. This performance improvement of $\mathrm{K}-\mathrm{V}_{2} \mathrm{C}$ compared to $\mathrm{V}_{2} \mathrm{C}$ could be due to the presence of abundant pores in $\mathrm{K}-\mathrm{V}_{2} \mathrm{C}$, which can facilitate the electrolyte diffusion and permeation. In addition, the much thinner nanosheets of $\mathrm{K}-\mathrm{V}_{2} \mathrm{C}$ provide a larger electrochemically active surface area which allows enhanced $\mathrm{K}^{+}$intercalation into the gallery, as well as more $\mathrm{K}^{+}$adsorption onto the surface and edges. This can be further confirmed by the cyclic voltammetry (CV) result. Figure 3C shows the $\mathrm{CV}$ plots of the $\mathrm{V}_{2} \mathrm{C}$ and $\mathrm{K}-\mathrm{V}_{2} \mathrm{C}$ electrodes at the second and third cycles. Both electrodes exhibit a rectangular-shaped $\mathrm{CV}$ above $\sim 1.0 \mathrm{~V}$ vs. $\mathrm{K} / \mathrm{K}^{+}$, suggesting a typical capacitor behavior [46]. Additionally, in the region below $1.0 \mathrm{~V}$, a reversible pair of broad redox peaks are observed. The normalized current of the $\mathrm{K}-\mathrm{V}_{2} \mathrm{C}$ in both regions is obviously larger than that of the $\mathrm{V}_{2} \mathrm{C}$, indicating more charges are involved in the reaction (adsorption/desorption and intercalation/deintercalation), leading to a higher capacity. We further analyzed the electrochemical kinetics of $\mathrm{K}-\mathrm{V}_{2} \mathrm{C}$ and quantitatively calculated the capacitive contribution using a simple CV method (Figure 3D) [47]. The capacitive contribution gradually increases with increasing scan rates (from $56 \%$ at $0.1 \mathrm{mV} \mathrm{s}^{-1}$ to $74 \%$ at $0.5 \mathrm{mV} \mathrm{s}^{-1}$ ), which indicates that the reaction is mainly limited by the electrochemical reaction rate, but not the $\mathrm{K}^{+}$ion diffusion, especially at high rates. As discussed earlier, the reaction occurring above $1.0 \mathrm{~V}$ is dominated by capacitive behavior. Indeed, taking the $\mathrm{CV}$ at $0.3 \mathrm{mV} \mathrm{s}^{-1}$ as an example (Figure 3E), almost $86 \%$ of the current exhibits capacitive behavior in the region above $1.0 \mathrm{~V}$, in sharp contrast to $46 \%$ capacitive contribution in the region below $1.0 \mathrm{~V}$. Additionally, the $b$-values of the anodic and 
cathodic peaks (see Figure S9) are determined to be 0.83, 0.92, 0.91, 0.94, 0.86, and 0.85, again implying the charge storage is mostly dominated by capacitive behavior (Figure 3F). Note that the $b$-values in the region above $1.0 \mathrm{~V}(\mathrm{~A} 2, \mathrm{~A} 3$, and $\mathrm{C} 1)$ are generally higher than those in the region below 1.0 V (A1, C2, C3), which is in good agreement with the result shown in Figure 3E. The Galvanostatic intermittent titration technique (GITT) was employed to determine the $\mathrm{K}^{+}$ion diffusion coefficients (Figure 3G-H). The result shows that the diffusion coefficients of $\mathrm{K}^{+}$in $\mathrm{K}-$ $\mathrm{V}_{2} \mathrm{C}\left(10^{-10}\right.$ to $\left.10^{-12} \mathrm{~cm}^{2} \mathrm{~s}^{-1}\right)$ are higher than in $\mathrm{V}_{2} \mathrm{C}\left(10^{-11}\right.$ to $\left.10^{-13} \mathrm{~cm}^{2} \mathrm{~s}^{-1}\right)$ throughout the whole discharge-charge process. This result shows that the porous $\mathrm{K}-\mathrm{V}_{2} \mathrm{C}$ with thinner nanosheets can achieve a faster $\mathrm{K}^{+}$migration compared to the pristine $\mathrm{V}_{2} \mathrm{C}$. Figure 3I plots the $\mathrm{K}^{+}$diffusion coefficients at various states during the discharging process of the $\mathrm{K}-\mathrm{V}_{2} \mathrm{C}$. Again, the result is very consistent with the above analysis and discussion, which clearly shows that $\mathrm{K}^{+}$diffusion coefficients above $1.0 \mathrm{~V}$ are higher than those below $1.0 \mathrm{~V}$.

Another advantage of the $\mathrm{K}-\mathrm{V}_{2} \mathrm{C}$ electrode is the improved coulombic efficiency (CE). The CEs of MXene electrodes are typically low compared to other materials owing to the abundant functional groups on MXene surface, and the solid-electrolyte interphase (SEI) formation in the initial stages. As shown in Figure S10, the first cycle CE is greatly increased from $22.5 \%$ for the $\mathrm{V}_{2} \mathrm{C}$ electrode to $41.6 \%$ for the $\mathrm{K}-\mathrm{V}_{2} \mathrm{C}$ electrode. Moreover, this value quickly reaches $97.1 \%$ in the $5^{\text {th }}$ cycle for $\mathrm{K}-\mathrm{V}_{2} \mathrm{C}$ electrode. In contrast, the $\mathrm{CE}$ is only $87.4 \%$ for $\mathrm{V}_{2} \mathrm{C}$ even at the $10^{\text {th }}$ cycle. There are several possible reasons for the better $\mathrm{CE}$ observed for $\mathrm{K}-\mathrm{V}_{2} \mathrm{C}$. After the alkaline treatment, the surface area almost doubled but is still significantly lower than the common porous electrode. The larger surface area might lead to relatively more SEI formation, but the influence is supposed to be limited given the small surface area $\left(28.4 \mathrm{~m}^{2} \mathrm{~g}^{-1}\right)$. However, the alkaline treatment 
could also affect the surface functional groups (as confirmed by XPS, Figure 2), which might promote the efficient extraction of surface trapped $\mathrm{K}^{+}$, which is responsible for the improved initial CE. Besides, the alkaline treatment can pre-intercalate the K-ion (as confirmed by EDS and ICPOES) which can reduce the amount of irreversible $\mathrm{K}$-ion, thus improving the initial CE. The cycling stabilities of the two electrodes were tested at a standard current density of $100 \mathrm{~mA} \mathrm{~g}^{-1}$. As shown in Figure S11, both electrodes show good performance with $\sim 81 \%$ capacity retention (against the capacities of 152 and $73 \mathrm{mAh} \mathrm{g}^{-1}$ of $\mathrm{K}-\mathrm{V}_{2} \mathrm{C}$ and $\mathrm{V}_{2} \mathrm{C}$ at the $10^{\text {th }}$ cycle, respectively). What's more, $\sim 77 \%$ capacity can be still maintained after 400 cycles (against the stable capacity of $113 \mathrm{mAh} \mathrm{g}^{-1}$ at the $15^{\text {th }}$ cycle for the $\mathrm{K}-\mathrm{V}_{2} \mathrm{C}$ electrode even at a high rate of $500 \mathrm{~mA} \mathrm{~g}^{-1}$ (Figure S12).

Previous reports revealed that the energy storage behaviors of the MXenes are intricate and complicated. For instance, Lukatskaya et al. [48] reported spontaneous cation intercalation of $\mathrm{Ti}_{3} \mathrm{C}_{2}$ MXene in various aqueous salts (e.g., $\mathrm{LiOH}, \mathrm{NaOH}, \mathrm{KOH}$, and so on). However, in nonaqueous $\mathrm{NaPF}_{6} / \mathrm{EC}-\mathrm{DEC}$ (ethylene carbonate-diethyl carbonate) electrolyte, the cation intercalation does not occur [44]. Moreover, $\mathrm{V}_{2} \mathrm{C}$ MXene in a nonaqueous $\mathrm{Li}^{+}$electrolyte exhibits a reversible change in the interlayer spacing upon the charge/discharge process [37]. However, in a nonaqueous $\mathrm{Na}^{+}$electrolyte, an irreversible change of the interlayer spacing was found for $\mathrm{Ti}_{3} \mathrm{C}_{2}$ [49], $\mathrm{Ti}_{2} \mathrm{C},[46]$ and $\mathrm{V}_{2} \mathrm{C}$ [50] electrodes. It is therefore likely that the charge storage mechanism in nonaqueous $\mathrm{K}^{+}$electrolytes could be different from those in $\mathrm{Li}^{+}$and $\mathrm{Na}^{+}$electrolytes and is worth further investigation. To gain insight into the $\mathrm{K}^{+}$ion storage behavior, ex situ XPS, XRD, and nuclear magnetic resonance (NMR) were carried out. Figure S13A displays the XPS spectra of $\mathrm{K} 2 \mathrm{p}$ region of the $\mathrm{K}-\mathrm{V}_{2} \mathrm{C}$ electrode at different states. The peaks become much more intense 
in the fully discharged state, indicating the insertion/adsorption of $\mathrm{K}^{+}$ions. The shift to higher binding energy could be caused by the changes in the chemical environment and/or the structure rearrangement. At the fully charged state, the peak intensity weakens but is stronger than the original one, suggesting some of the intercalated $\mathrm{K}^{+}$ions are trapped by the terminal functional groups $(-\mathrm{OH},-\mathrm{O}$, and $-\mathrm{F})$. This effect is similar to reported phenomena in sodium ion batteries $[46,49,50]$, and indicates that $\mathrm{K}^{+}$might be trapped in between the MXene interlayers, where they serve as pillars to stabilize the structure (as will be discussed later). Figure S13B reveals the reversible reduction/oxidation of vanadium upon potassiation/depotassiation. Specifically, the $\mathrm{V}^{4+}$ is reduced to $\mathrm{V}^{3+}$ during the discharge process (the blue shift of the $\mathrm{V}^{3+}$ binding energy may be linked to the insertion of $\mathrm{K}^{+}$ions and the concomitant bonding rearrangements; similar phenomena have been seen in previous reports $[12,51,52])$, but almost recovers to its initial state upon charging.
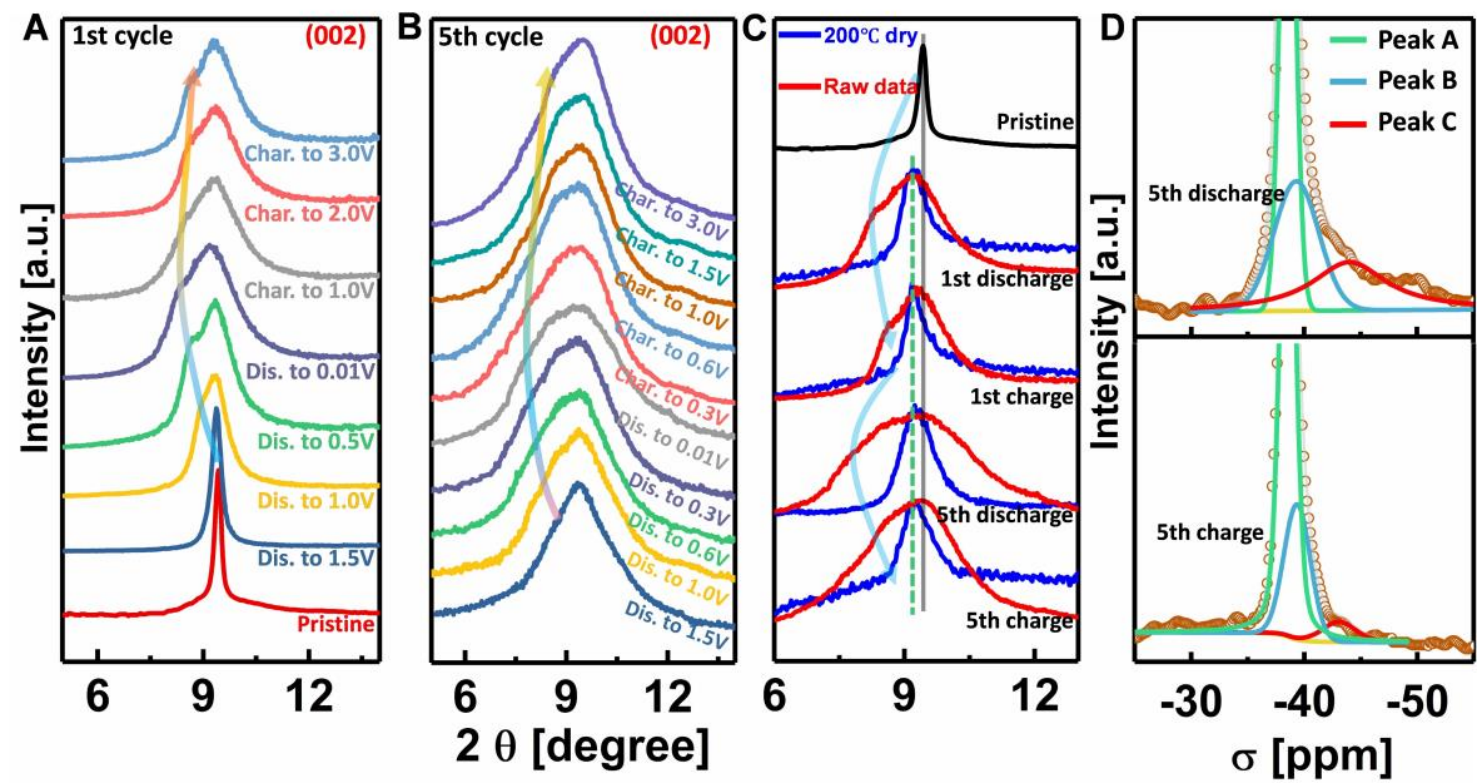

Figure 4. Ex-situ (A-C) XRD patterns and (D) ${ }^{39} \mathrm{~K}$ NMR spectra of the $\mathrm{K}-\mathrm{V}_{2} \mathrm{C}$ electrode at various charge/discharge states. 
Ex-situ XRD measurement was carried out to monitor the phase and structure change during the charge/discharge process. Obvious lattice changes can be observed in the (002) diffraction peak at different charging/discharging states (Figure 4). During the $1^{\text {st }}$ discharge process, the sharp diffraction peak slightly shifts to lower $2 \theta$ angle and becomes broader. Surprisingly, a new peak emerges at the lower $2 \theta$ position when the battery was discharged to $1.0 \mathrm{~V}$. This new peak slightly shifts to lower $2 \theta$ angle but still remains upon charging to $3.0 \mathrm{~V}$. Notably, the (002) peak also becomes broader and doesn't recover back to the initial position even at the cut-off voltage. To further understand this situation, we collected ex-situ XRD patterns of the $\mathrm{K}-\mathrm{V}_{2} \mathrm{C}$ electrode in the $5^{\text {th }}$ cycle (Figure 4B). Interestingly, unlike what we observed for the $1^{\text {st }}$ cycle, the (002) diffraction peak shows a reversible shift. A more intuitive comparison is shown in Figure 4C. For both the $1^{\text {st }}$ and $5^{\text {th }}$ cycles (red lines), the (002) peak becomes broader and slightly shifts to low angle during the discharge process, and then narrows down upon charging. In analogy with previous reports on sodium ion storage in MXene $[46,49,50]$, we suspected that this effect (appearance of a new peak in XRD) is caused by solvent co-intercalation along with the $\mathrm{K}^{+}$ions. While in the fully charged state, a clear diffraction peak change is observed, indicating that a certain amount of solvated $\mathrm{K}^{+}$ ions is trapped between the layers, which is consistent with the XPS result in Figure S13A [46, $49,50]$. To verify this hypothesis, the electrodes at fully charged/discharged states of the $1^{\text {st }}$ and $5^{\text {th }}$ cycles were dried at $200{ }^{\circ} \mathrm{C}$ in a vacuum oven to evaporate the organic solvent. The XRD patterns of the resulting products are shown in Figure 4C (blue lines). It is interesting to see that the additional peak, observed before drying, disappears and all these four samples show much sharper diffraction patterns than those of the samples without high-temperature drying. This result confirms our solvent intercalation hypothesis. It is noted that the (002) peaks of the dried samples are located at a lower $2 \theta$ angle compared to that of the pristine sample, corresponding to an increase 
in the interlayer distance from 9.38 to $9.63 \AA$. This suggests that a certain amount of $\mathrm{K}^{+}$ions remain trapped between the interlayers. HRTEM was further carried out to explore the evolution of the interlayer spacing. As shown in Figure S14, the interlayer spacing of the pristine electrode is determined to be $\sim 0.94 \mathrm{~nm}$ from HRTEM (Figure S14A). At the fully discharged state of the $10^{\text {th }}$ cycle, the interlayer spacing expanded to $\sim 0.995 \mathrm{~nm}$ (Figure S14B), and then reversibly shrank to $0.97 \mathrm{~nm}$ at the fully charged state (Figure S14C). These results are good in accordance with the $\mathrm{XRD}$ results (Figure 4).

Further, ${ }^{39} \mathrm{~K}$ NMR was utilized to explore the $\mathrm{K}^{+}$ion storage behavior. As shown in Figure 4D, the spectra display a signal ranging from -50 to $-30 \mathrm{ppm}$, which can be fitted into three peaks. The peak A (green line) centered at $-38.5 \mathrm{ppm}$ is assigned to solvated $\mathrm{K}^{+}$from the residual electrolyte because of its line width [53,54], whereas the other two (B and C, cyan and red lines, respectively) indicate the existence of two different $\mathrm{K}^{+}$ions. Specifically, peak A appears at the negative frequency because the $\mathrm{K}^{+}$in the electrolyte is strongly shielded by the electron donated from the solvent and counter-anions [54]. Peak B has a similar negative chemical shift (-39.3 ppm), while the broader line width suggests lower mobility of solvated $\mathrm{K}^{+}$. This type of $\mathrm{K}^{+}$can be assigned to the adsorbed $\mathrm{K}^{+}$on the surface and edges of the $\mathrm{K}-\mathrm{V}_{2} \mathrm{C}$ nanosheets, as well as the $\mathrm{K}^{+}$ in the SEI. In contrast, peak $\mathrm{C}$ exhibits a larger negative shift with much more broader line width, indicating a stronger shielding effect and lowest mobility. This could be explained by the strong interaction between the solvated (or at least partially solvated) $\mathrm{K}^{+}$ions and the neighboring $\mathrm{V}_{2} \mathrm{C}$ layers. Based on the above assignment, ex-situ NMR spectra of the $5^{\text {th }}$ cycle (fully discharged and charged states) prove the reversible solvated $\mathrm{K}^{+}$(de)insertion where peak $\mathrm{C}$ is much more intense in the fully discharged state compared to the charged state. 
The results shown above confirm a reversible solvent co-(de)intercalation process. As schematically shown in Figure S15, in the initial few cycles, the electrolyte decomposition leads to the SEI formation. Simultaneously, a certain amount of solvated $\mathrm{K}^{+}$ions is trapped inside the layers during the (de)intercalation process, resulting in irreversible expansion of the interlayer distance ("activation" process). Such a pillared structure is also responsible for the good rate performance and long-term stability of the $\mathrm{K}-\mathrm{V}_{2} \mathrm{C}$ MXene. Thereafter, reversible adsorption/desorption and intercalation/deintercalation of the solvated $\mathrm{K}^{+}$proceeds as the dominant electrochemical reaction.
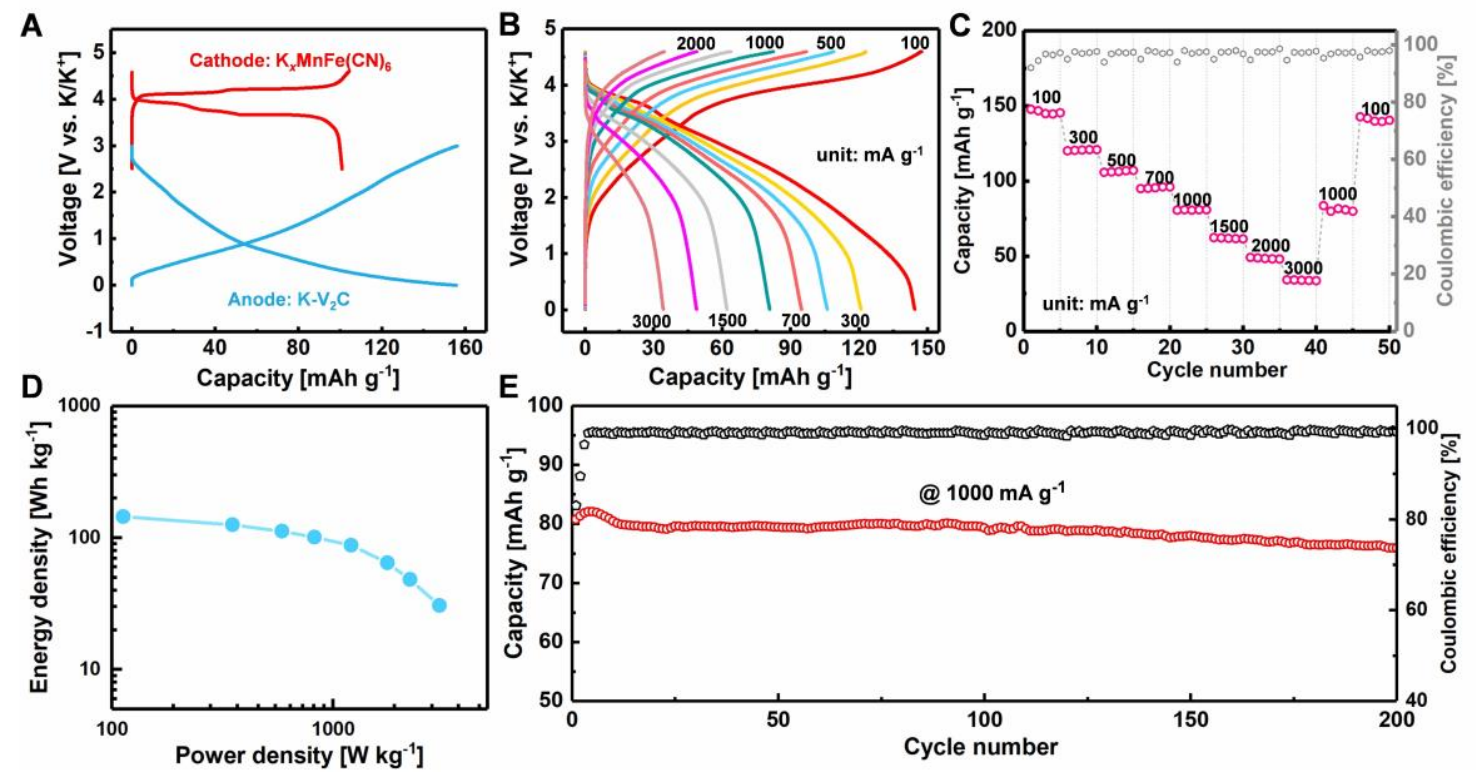

Figure 5. Electrochemical characterization of the $\mathrm{K}^{+}$ion capacitor devices. (A) Galvanostatic charge/discharge curves of the cathode and anode. (B) Galvanostatic charge/discharge curves of the full cell at various current densities (based on the mass of the $\mathrm{K}-\mathrm{V}_{2} \mathrm{C}$ ). (C) Rate performance of the full cell. (D) The Ragone plot of $\mathrm{K}-\mathrm{V}_{2} \mathrm{C} / / \mathrm{K}_{x} \mathrm{MnFe}(\mathrm{CN})_{6}$ cell. (E) Cycling performance of the device at $1000 \mathrm{~mA} \mathrm{~g}^{-1}$. 
To further demonstrate the potential of $\mathrm{K}-\mathrm{V}_{2} \mathrm{C}$ in $\mathrm{K}^{+}$ion capacitors, full cells were fabricated by coupling the $\mathrm{K}-\mathrm{V}_{2} \mathrm{C}$ anode and Prussian blue analogue $\mathrm{K}_{x} \mathrm{MnFe}(\mathrm{CN})_{6}$ cathode. We chose $\mathrm{K}_{x} \mathrm{MnFe}(\mathrm{CN})_{6}$ as the cathode based on the consideration of its suitable working voltage window (2.5 to $4.6 \mathrm{~V}$ vs. $\mathrm{K} / \mathrm{K}^{+}$) and relatively high capacity. Besides, $\mathrm{K}_{x} \mathrm{MnFe}(\mathrm{CN})_{6}$ is low-cost and easy to prepare. The cathode was prepared by a previously reported method [55]. The XRD pattern and SEM image can be seen in Figure S16A and B. As shown in Figure S16C and D, the cathode exhibits a high capacity of $100 \mathrm{mAh} \mathrm{g}^{-1}$ at $50 \mathrm{~mA} \mathrm{~g}^{-1}$. As shown in Figure $\mathbf{S 1 7}$, the cathode shows good stability which maintains $92 \%$ initial capacity after 150 charge/discharge cycles at $100 \mathrm{~mA}$ $\mathrm{g}^{-1}$. More importantly, a high average operating potential of $\sim 3.7 \mathrm{~V}\left(\mathrm{vs} . \mathrm{K} / \mathrm{K}^{+}\right.$) can be obtained. Thus both high energy density and power density can be expected in the $\mathrm{K}^{+}$ion full cell. According to the capacities of the cathode and anode (Figure 5A), the mass ratio of the cathode and anode was optimized at $\sim 1.55: 1$. As shown in Figure 5B and C, the $\mathrm{K}^{+}$ion capacitor can work with a high average operating voltage of $\sim 3.3 \mathrm{~V}$ within a wide potential range from $0.01 \mathrm{~V}$ to $4.6 \mathrm{~V}$. A high capacity of $145 \mathrm{mAh} \mathrm{g}^{-1}$ can be obtained at $100 \mathrm{~mA} \mathrm{~g}^{-1}$ (based on the mass of $\mathrm{K}-\mathrm{V}_{2} \mathrm{C}$ ). Moreover, the reversible capacity is retained even at high rates, achieving capacities of 107,80 , 48, and $34 \mathrm{mAh} \mathrm{g}^{-1}$ at 500,1000, 2000, and $3000 \mathrm{~mA} \mathrm{~g}^{-1}$, respectively. Additionally, as displayed in Figure 5D, the $\mathrm{K}^{+}$ion capacitor can achieve the energy densities of 145 and $30.55 \mathrm{Wh} \mathrm{kg}^{-1}$ at the power densities of 112.6 and $3026 \mathrm{~W} \mathrm{~kg}^{-1}$, respectively (based on the total active mass of the cathode and anode). The long-term stability of the full cell was tested at a high rate of $1000 \mathrm{~mA}$ $\mathrm{g}^{-1}$, a capacity of $76 \mathrm{mAh} \mathrm{g}^{-1}$ can be maintained after 200 cycles, corresponding to $95 \%$ capacity retention (against the capacity of the first cycle, $80 \mathrm{mAh} \mathrm{g}^{-1}$ ). This result demonstrates the good performance of the $\mathrm{K}-\mathrm{V}_{2} \mathrm{C}$ MXene and its potential in practical energy storage devices.

\section{Conclusions}


We have developed a simple yet versatile sequential acid/alkali treatment to prepare porous MXene nanosheets and further investigated their electrochemical properties. Using $\mathrm{V}_{2} \mathrm{C}$ MXene as a model system, we showed that the dual acid/alkali-treated sample $\left(\mathrm{K}-\mathrm{V}_{2} \mathrm{C}\right)$ exhibits a significant enhancement towards $\mathrm{K}^{+}$ion storage in nonaqueous electrolytes compared to pristine $\mathrm{V}_{2} \mathrm{C}$ MXene. The charge storage mechanism was demonstrated to be a result of solvent cointercalation process, as confirmed by multiple characterizations methods. Further, a $\mathrm{K}^{+}$ion capacitor was successfully fabricated by coupling the $\mathrm{K}-\mathrm{V}_{2} \mathrm{C}$ anode and $\mathrm{K}_{x} \mathrm{MnFe}(\mathrm{CN})_{6}$ cathode to demonstrate the practical potential of $\mathrm{K}-\mathrm{V}_{2} \mathrm{C}$. The device can achieve a high energy density of 145 Wh $\mathrm{kg}^{-1}$ at a power density of $112.6 \mathrm{~W} \mathrm{~kg}^{-1}$. Our work demonstrates a general strategy for synthesizing various MXenes with porous nanosheet structures, as effective electrodes for mobile ion capacitors and other energy storage devices.

\section{Corresponding Author}

* e-mail: husam.alshareef@kaust.edu.sa

\section{Author Contributions}

The manuscript was written through the contributions of all authors. All authors have given approval to the final version of the manuscript.

\section{ACKNOWLEDGMENT}

The research reported in this publication was supported by King Abdullah University of Science and Technology (KAUST). Authors thank the Advanced Nanofabrication, Imaging and Characterization Laboratory at KAUST for their excellent support. 


\section{References:}

[1] M. Armand, J.-M. Tarascon, Building better batteries, Nature, 451 (2008) 652.

[2] M.R. Palacin, Recent Advances in Rechargeable Battery Materials: A Chemist's Perspective, Chem. Soc. Rev., 38 (2009) 2565-2575.

[3] B. Dunn, H. Kamath, J.-M. Tarascon, Electrical Energy Storage for the Grid: A Battery of Choices, Science, 334 (2011) 928-935.

[4] Y. Tang, Y. Zhang, W. Li, B. Ma, X. Chen, Rational Material Design for Ultrafast Rechargeable Lithium-Ion Batteries, Chem. Soc. Rev., 44 (2015) 5926-5940.

[5] M.D. Slater, D. Kim, E. Lee, C.S. Johnson, Sodium-Ion Batteries, Adv. Funct.Mater., 23 (2013) 947-958.

[6] F. Ming, H. Liang, Y. Lei, W. Zhang, H.N. Alshareef, Solution Synthesis of VSe $\mathrm{Nanosheets}^{2}$ and Their Alkali Metal Ion Storage Performance, Nano Energy, 53 (2018) 11-16.

[7] F. Zhang, C. Xia, J. Zhu, B. Ahmed, H. Liang, D.B. Velusamy, U. Schwingenschlögl, H.N. Alshareef, $\mathrm{SnSe}_{2} 2 \mathrm{D}$ Anodes for Advanced Sodium Ion Batteries, Adv. Energy Mater., 6 (2016) 1601188 .

[8] M.M. Huie, D.C. Bock, E.S. Takeuchi, A.C. Marschilok, K.J. Takeuchi, Cathode Materials for Magnesium and Magnesium-Ion Based Batteries, Coord. Chem. Rev., 287 (2015) 15-27.

[9] J. Song, M. Noked, E. Gillette, J. Duay, G. Rubloff, S.B. Lee, Activation of a $\mathrm{MnO}_{2} \mathrm{Cathode}$ by Water-Stimulated $\mathrm{Mg}^{2+}$ Insertion for a Magnesium Ion Battery, Phys. Chem. Chem. Phys., 17 (2015) 5256-5264.

[10] J. Ming, J. Guo, C. Xia, W. Wang, H.N. Alshareef, Zinc-Ion Batteries: Materials, Mechanisms, and Applications, Mater. Sci. Eng. R Rep., 135 (2019) 58-84.

[11] A. Konarov, N. Voronina, J.H. Jo, Z. Bakenov, Y.-K. Sun, S.-T. Myung, Present and Future Perspective on Electrode Materials for Rechargeable Zinc-Ion Batteries, ACS Energy Lett., 3 (2018) 2620-2640.

[12] F. Ming, H. Liang, Y. Lei, S. Kandambeth, M. Eddaoudi, H.N. Alshareef, Layered $\mathrm{Mg}_{x} \mathrm{~V}_{2} \mathrm{O}_{5} \cdot n \mathrm{H}_{2} \mathrm{O}$ as Cathode Material for High Performance Aqueous Zinc Ion Batteries, ACS Energy Lett., 3 (2018) 2602-2609.

[13] D. Larcher, J.-M. Tarascon, Towards Greener and More Sustainable Batteries for Electrical Energy Storage, Nat. Chem., 7 (2015) 19.

[14] Y.-H. Zhu, X. Yang, D. Bao, X.-F. Bie, T. Sun, S. Wang, Y.-S. Jiang, X.-B. Zhang, J.-M. Yan, Q. Jiang, High-Energy-Density Flexible Potassium-Ion Battery Based on Patterned Electrodes, Joule, 2 (2018) 736-746.

[15] J.-Y. Hwang, S.-T. Myung, Y.-K. Sun, Recent Progress in Rechargeable Potassium Batteries, Adv. Funct. Mater., 28 (2018) 1802938.

[16] C. Yang, J. Feng, F. Lv, J. Zhou, C. Lin, K. Wang, Y. Zhang, Y. Yang, W. Wang, J. Li, Metallic Graphene-Like VSe 2 Ultrathin Nanosheets: Superior Potassium-Ion Storage and Their 
Working Mechanism, Adv. Mater., 30 (2018) 1800036.

[17] M.W. Barsoum, MAX Phases: Properties of Machinable Ternary Carbides and Nitrides, John Wiley \& Sons 2013.

[18] M. Naguib, J. Come, B. Dyatkin, V. Presser, P.-L. Taberna, P. Simon, M.W. Barsoum, Y. Gogotsi, MXene: A Promising Transition Metal Carbide Anode for Lithium-Ion Batteries, Electrochem. Commun., 16 (2012) 61-64.

[19] B. Anasori, M.R. Lukatskaya, Y. Gogotsi, 2D Metal Carbides and Nitrides (MXenes) for Energy Storage, Nat. Rev. Mater., 2 (2017) 16098.

[20] N. Kurra, B. Ahmed, Y. Gogotsi, H.N. Alshareef, MXene-on-Paper Coplanar Microsupercapacitors, Adv. Energy Mater., 6 (2016) 1601372.

[21] Q. Jiang, N. Kurra, M. Alhabeb, Y. Gogotsi, H.N. Alshareef, All Pseudocapacitive MXeneRuO2 Asymmetric Supercapacitors, Adv. Energy Mater., 8 (2018) 1703043.

[22] N. Kurra, M. Alhabeb, K. Maleski, C.-H. Wang, H.N. Alshareef, Y. Gogotsi, Bistacked Titanium Carbide (MXene) Anodes for Hybrid Sodium-Ion Capacitors, ACS Energy Lett., 3 (2018) 2094-2100.

[23] F. Du, H. Tang, L. Pan, T. Zhang, H. Lu, J. Xiong, J. Yang, C.J. Zhang, Environmental Friendly Scalable Production of Colloidal 2D Titanium Carbonitride MXene with Minimized Nanosheets Restacking for Excellent Cycle Life Lithium-Ion Batteries, Electrochimi. Acta, 235 (2017) 690-699.

[24] D. Zhao, M. Clites, G. Ying, S. Kota, J. Wang, V. Natu, X. Wang, E. Pomerantseva, M. Cao, M.W. Barsoum, Alkali-Induced Crumpling of $\mathrm{Ti}_{3} \mathrm{C}_{2} \mathrm{~T}_{\mathrm{x}}$ (MXene) to Form 3D Porous Networks for Sodium Ion Storage, Chem. Commun., 54 (2018) 4533-4536.

[25] X. Xie, K. Kretschmer, B. Anasori, B. Sun, G. Wang, Y. Gogotsi, Porous $\mathrm{Ti}_{3} \mathrm{C}_{2} \mathrm{~T}_{\mathrm{x}} \mathrm{MXene}$ for Ultrahigh-Rate Sodium-Ion Storage with Long Cycle Life, ACS Appl. Nano Mater., 1 (2018) 505511.

[26] M.R. Lukatskaya, S. Kota, Z. Lin, M.-Q. Zhao, N. Shpigel, M.D. Levi, J. Halim, P.-L. Taberna, M.W. Barsoum, P. Simon, Ultra-High-Rate Pseudocapacitive Energy Storage in TwoDimensional Transition Metal Carbides, Nat. Energy, 2 (2017) 17105.

[27] F. Ming, H. Liang, H. Shi, G. Mei, X. Xu, Z. Wang, Hierarchical (Ni, Co) $\mathrm{Se}_{2} /$ Carbon Hollow Rhombic Dodecahedra Derived from Metal-Organic Frameworks for Efficient Water-Splitting Electrocatalysis, Electrochimi. Acta, 250 (2017) 167-173.

[28] Q. Tang, Z. Zhou, P. Shen, Are MXenes Promising Anode Materials for Li Ion Batteries? Computational Studies on Electronic Properties and Li Storage Capability of $\mathrm{Ti}_{3} \mathrm{C}_{2}$ and $\mathrm{Ti}_{3} \mathrm{C}_{2} \mathrm{X}_{2}$ (X= F, OH) monolayer, J. Am. Chem. Soc., 134 (2012) 16909-16916.

[29] A. Lipatov, M. Alhabeb, M.R. Lukatskaya, A. Boson, Y. Gogotsi, A. Sinitskii, Effect of Synthesis on Quality, Electronic Properties and Environmental Stability of Individual Monolayer $\mathrm{Ti}_{3} \mathrm{C}_{2}$ MXene Flakes, Adv. Electron. Mater., 2 (2016) 1600255.

[30] J.-C. Lei, X. Zhang, Z. Zhou, Recent Advances in MXene: Preparation, Properties, and 
Applications, Front. Phys., 10 (2015) 276-286.

[31] C. Eames, M.S. Islam, Ion Intercalation into Two-Dimensional Transition-Metal Carbides: Global Screening for New High-Capacity Battery Materials, J. Am. Chem. Soc., 136 (2014) 16270-16276.

[32] Y. Xie, Y. Dall-Agnese, M. Naguib, Y. Gogotsi, M.W. Barsoum, H.L. Zhuang, P.R. Kent, Prediction and Characterization of MXene Nanosheet Anodes for Non-Lithium-Ion Batteries, ACS Nano, 8 (2014) 9606-9615.

[33] Y. Xie, M. Naguib, V.N. Mochalin, M.W. Barsoum, Y. Gogotsi, X. Yu, K.-W. Nam, X.-Q. Yang, A.I. Kolesnikov, P.R. Kent, Role of Surface Structure on Li-Ion Energy Storage Capacity of Two-Dimensional Transition-Metal Carbides, J. Am. Chem. Soc., 136 (2014) 6385-6394.

[34] M. Naguib, J. Halim, J. Lu, K.M. Cook, L. Hultman, Y. Gogotsi, M.W. Barsoum, New TwoDimensional Niobium and Vanadium Carbides as Promising Materials for Li-Ion Batteries, J. Am. Chem. Soc., 135 (2013) 15966-15969.

[35] Y. Dal-Agnese, P.-L. Taberna, Y. Gogotsi, P. Simon, Two-Dimensional Vanadium Carbide (MXene) as Positive Electrode for Sodium-Ion Capacitors, J. Phys. Chem. Lett., 6 (2015) 23052309.

[36] A. VahidMohammadi, A. Hadjikhani, S. Shahbazmohamadi, M. Beidaghi, Two-Dimensional Vanadium Carbide (MXene) as a High-Capacity Cathode Material for Rechargeable Aluminum Batteries, ACS Nano, 11 (2017) 11135-11144.

[37] C. Wang, H. Xie, S. Chen, B. Ge, D. Liu, C. Wu, W. Xu, W. Chu, G. Babu, P.M. Ajayan, Atomic Cobalt Covalently Engineered Interlayers for Superior Lithium-Ion Storage, Adv. Mater., 30 (2018) 1802525.

[38] A. Byeon, A.M. Glushenkov, B. Anasori, P. Urbankowski, J. Li, B.W. Byles, B. Blake, K.L. Van Aken, S. Kota, E. Pomerantseva, Lithium-Ion Capacitors with 2D $\mathrm{Nb}_{2} \mathrm{CT}_{\mathrm{x}}$ (MXene)-Carbon Nanotube Electrodes, J. Power Sources, 326 (2016) 686-694.

[39] G. Ying, S. Kota, A.D. Dillon, A.T. Fafarman, M.W. Barsoum, Conductive Transparent $\mathrm{V}_{2} \mathrm{CT}_{\mathrm{x}}$ (MXene) Films, FlatChem, 8 (2018) 25-30.

[40] A. Champagne, L. Shi, T. Ouisse, B. Hackens, J.-C. Charlier, Electronic and Vibrational Properties of $\mathrm{V}_{2} \mathrm{C}$-Based MXenes: From Experiments to First-Principles Modeling, Phys. Rev. B, 97 (2018) 115439.

[41] J.E. Spanier, S. Gupta, M. Amer, M.W. Barsoum, Vibrational behavior of the $M_{n+1} A X_{n}$ Phases from First-Order Raman Scattering ( $\mathrm{M}=\mathrm{Ti}, \mathrm{V}, \mathrm{Cr}, \mathrm{A}=\mathrm{Si}, \mathrm{X}=\mathrm{C}, \mathrm{N})$, Phys. Rev. B, 71 (2005) 012103.

[42] Z. Popović, M. Konstantinović, V. Moshchalkov, M. Isobe, Y. Ueda, Raman Scattering Study of Charge Ordering in $\beta-\mathrm{Ca}_{0.33} \mathrm{~V}_{2} \mathrm{O}_{5}$, J. Phys. Condens. Matter, 15 (2003) L139.

[43] P. Miao, J. Wu, Y. Du, Y. Sun, P. Xu, Phase Transition Induced Raman Enhancement on Vanadium Dioxide $\left(\mathrm{VO}_{2}\right)$ Nanosheets, J. Mater. Chem. C, 6 (2018) 10855-10860.

[44] J. Huang, R. Meng, L. Zu, Z. Wang, N. Feng, Z. Yang, Y. Yu, J. Yang, Sandwich-Like 
$\mathrm{Na}_{0.23} \mathrm{TiO}_{2}$ Nanobelt/ $\mathrm{Ti}_{3} \mathrm{C}_{2}$ MXene Composites from a Scalable in Situ Transformation Reaction for Long-Life High-Rate Lithium/Sodium-Ion Batteries, Nano Energy, 46 (2018) 20-28.

[45] M. Naguib, R.A. Adams, Y. Zhao, D. Zemlyanov, A. Varma, J. Nanda, V.G. Pol, Electrochemical Performance of MXenes as K-Ion Battery Anodes, Chem. Commun., 53 (2017) 6883-6886.

[46] X. Wang, S. Kajiyama, H. Iinuma, E. Hosono, S. Oro, I. Moriguchi, M. Okubo, A. Yamada, Pseudocapacitance of MXene Nanosheets for High-Power Sodium-Ion Hybrid Capacitors, Nat. Commun., 6 (2015) 6544.

[47] J. Wang, J. Polleux, J. Lim, B. Dunn, Pseudocapacitive Contributions to Electrochemical Energy Storage in $\mathrm{TiO}_{2}$ (anatase) Nanoparticles, J. Phys. Chem. C, 111 (2007) 14925-14931.

[48] M.R. Lukatskaya, O. Mashtalir, C.E. Ren, Y. Dall-Agnese, P. Rozier, P.L. Taberna, M. Naguib, P. Simon, M.W. Barsoum, Y. Gogotsi, Cation Intercalation and High Volumetric Capacitance of Two-Dimensional Titanium Carbide, Science, 341 (2013) 1502-1505.

[49] S. Kajiyama, L. Szabova, K. Sodeyama, H. Iinuma, R. Morita, K. Gotoh, Y. Tateyama, M. Okubo, A. Yamada, Sodium-Ion Intercalation Mechanism in MXene Nanosheets, ACS Nano, 10 (2016) 3334-3341.

[50] S.-M. Bak, R. Qiao, W. Yang, S. Lee, X. Yu, B. Anasori, H. Lee, Y. Gogotsi, X.-Q. Yang, Na-Ion Intercalation and Charge Storage Mechanism in 2D Vanadium Carbide, Adv. Energy Mater., 7 (2017) 1700959.

[51] D. Kundu, B.D. Adams, V. Duffort, S.H. Vajargah, L.F. Nazar, A High-Capacity and LongLife Aqueous Rechargeable Zinc Battery Using a Metal Oxide Intercalation Cathode, Nat. Energy, 1 (2016) 16119.

[52] N. Zhang, Y. Dong, M. Jia, X. Bian, Y. Wang, M. Qiu, J. Xu, Y. Liu, L. Jiao, F. Cheng, Rechargeable Aqueous $\mathrm{Zn}-\mathrm{V}_{2} \mathrm{O}_{5}$ Battery with High Energy Density and Long Cycle Life, ACS Energy Lett., 3 (2018) 1366-1372.

[53] K. Gotoh, M. Izuka, J. Arai, Y. Okada, T. Sugiyama, K. Takeda, H. Ishida, In Situ ${ }^{7}$ Li Nuclear Magnetic Resonance Study of the Relaxation Effect in Practical Lithium Ion Batteries, Carbon, 79 (2014) 380-387.

[54] R. Alcántara, P. Lavela, G.F. Ortiz, J.L. Tirado, Carbon Microspheres Obtained from Resorcinol-Formaldehyde as High-Capacity Electrodes for Sodium-Ion Batteries, Electrochem. Solid-State Lett., 8 (2005) A222-A225.

[55] L. Xue, Y. Li, H. Gao, W. Zhou, X. Lü, W. Kaveevivitchai, A. Manthiram, J.B. Goodenough, Low-Cost High-Energy Potassium Cathode, J. Am. Chem. Soc., 139 (2017) 2164-2167. 